\title{
Computational Neuro-physiological Model (CNP) to Profile Lower Primary School Students in Inclusive Education: A Concept Paper
}

\author{
Norzaliza Md Nor ${ }^{1}$, Noor Azura Zakaria ${ }^{2}$, Muna Azuddin ${ }^{3}$, Murni Mahmud ${ }^{4}$, Abdul Wahab Abdul \\ Rahman $^{5}$, Ruwinah Abdul Karim ${ }^{6}$ \\ ${ }^{1,2,5}$ Department of Computer Science, Kulliyyah of Information and Communication Technology, International \\ Islamic University Malaysia, Malaysia \\ ${ }^{1}$ norzaliza@iium.edu.my, ${ }^{2}$ azurazakaria@iium.edu.my, ${ }^{5}$ abdulwahab@iium.edu.my \\ ${ }^{3,4}$ Department of Information Systems, Kulliyyah of Information and Communication Technology, \\ International Islamic University Malaysia, Malaysia \\ ${ }^{3}$ munaazuddin@iium.edu.my, ${ }^{4}$ murni@iium.edu.my \\ ${ }^{6}$ Penawar Special Learning Centre, Pasir Gudang, Malaysia, ruwinah@ hospitalpenawar.com
}

\begin{abstract}
Inclusive education (IE) is commonly accepted internationally as a standard right for all children. Malaysia has similar aspiration to implement the concept in the school system. However, it appears IE is challenging for parents, teachers and students. One of the challenges is to produce a well-trained and competent teacher to recognize learning abilities and disabilities of individual students. The Malaysian government is committed to ensure children to receive equality in education. Malaysia Education Blueprint (MEB) spells out $75 \%$ of children with learning disabilities must be part of IE by 2025. There is a gap in IE studies in terms of investigating the relationship between emotions and learning ability among students in IE environment. Therefore, this concept paper proposes a standard profiling model by using the Computational Neuro-physiological (CNP) model to profile lower primary school students in IE. This paper also emphasizes the possible use of EEG technology in detecting the emotion, behavior and mental state that can be used to indicate the student's learning ability in the inclusive education. This research is important to be carried out to have a student's profile which can be used to facilitate teachers to improve their competencies in teaching and handling the students.
\end{abstract}

Key words: Inclusive Education, Computational NeuroPhysiological (CNP), EEG, Brain Wave Pattern

\section{INTRODUCTION}

Malaysian education agenda that recognizes the Special Education Need (SEN) students starting in 1990's was a good initiative to ensure that no children are lacking behind in terms of education including those who unfortunate with physical, mental and learning disabilities [1]. In year 2019, the National Early Childhood Intervention Council mentioned that the inclusive education environment allows SEN students to develop their socialization and peer relationship.

Most research in inclusive education attempted to propose a solution mainly for inclusive education teachers to overcome their stress and also on the governance issues which basically involves with the statistical data [2-6]. It is important to study not only the teachers' point of view but also the students' perspective in the inclusive education. Perspective for both parties should be considered in order to create a stress-free environment during leaning process. Other studies proposed the utilization of Information and Communication Technology (ICT) in the learning process in the inclusive education. However, the proposed solutions have not taken the mental state information using EEG that capture brainwave signal which basically is not able to be modified or tampered. Human learning process is significantly influenced from emotional behavior of subject $[7,8]$ which can give either pleasant or unpleasant feeling during learning time.

The above-mentioned problems show that there is an absence of investigation on the relationship between emotion and learning ability among students in inclusive education environment. Therefore, this study will investigate the issue by using EEG technology to detect emotion, behavior and mental state in order to propose a standard profiling model that can be used to indicate the student's learning ability in the inclusive education. This is important for profiling purposes of students in inclusive education. The profiling may assist on the development of interventions that can give a holistic view in the inclusive education's learning process. In addition, the profiling may enable the teachers to have better understanding on the learning ability of students in the inclusive education to enhance their teaching skills and competency. 


\section{LITERATURE REVIEWS}

An initiative to have policies on children's rights has been done by United Nation (UN) and United Nations Educational, Scientific and Cultural Organisation (UNESCO). In addition, equality education opportunity that allows all children including Special Education Needs (SEN) was announced by UNESCO in 1994. Malaysia accepted the initiative by introducing inclusive education in the Malaysian Education Act 1996 to support children with learning difficulties. The concept of inclusive education originated from the special education whereby the agenda was defined in the Education Act 1996 [9]. SEN students consists of several categories for example physical disabilities, mental and behaviour disabilities, and special learning disabilities focuses on the reading, writing, and calculating [1].

Students with learning disabilities (LD) face many disorder challenges in terms of attention, mood, stress, behaviour, speech and many more [10]. Many researches proposed the use of Information and Communication Technology (ICT) to assist the LD students. A Computer-Assisted Learning (CAL) has been suggested through gamified intervention [11] and wearable sensor technologies [12]. In addition, multimedia also has been used in the inclusive education which resulting satisfaction among teachers and LD students and increase awareness in the use of the multimedia technology [13, 14]. The used of ICT is undoubted to assist both teachers and also LD students in the inclusive education. However, a thorough multidimensional analysis should be done to examine and evaluate both parties before any interventions can be proposed in the inclusive education setting [15]. This is to avoid creating stress intense especially to the LD students.

Emotions can provide many possibilities for enhancing the interaction with human subject using the emotion-based intelligent systems, e.g., affective interaction with autism or epilepsy patient [16]. Human learning process is significantly influenced from emotional behavior of subject $[7,8,17]$. More specifically, while students are attentive with pleasant feelings, they will definitely produce positive results. It is imperative to understand on how the emotions change in student's learning process especially for the LD students. By understanding the emotions change, many solutions and interventions can be proposed to assist the LD students in order for them to receive appropriate learning process [18]. Emotion, mood and stress are one of brain behaviors that can be measured and detected using Electroencephalography (EEG) through the brainwave signals. EEG is a technology that is widely used to record the electrical activity of a human brain and it was initially used by Hans Berger in 1924 [12]. The brainwaves are activated when it is stimulated externally. The brainwaves are direct reflection of the state of mind and cannot be tampered with [19]. In terms of EEG usage among the learning disabilities students, the technology is prominently being used to capture and measure the brainwave signals to detect their mood [10, 19], emotions [19-21] and stress level $[22,23]$. EEG has been successfully used to recognize and monitor cognitive processes that occur within the brain which related with inner thinking activities. The captured brainwaves signal later on will be analysed and processed and profiling can be produced. The information resides in the profiling may assist in proposing any interventions for LD students. Several literatures highlighted on the stress in inclusive education focusing on the teachers' perspective [26]. These studies proposed solutions to cope stress among the teachers by using data gathered through statistical method which measure the stress level among the teachers. A recent study by Mehmood and Lee [12] has attempted of using EEG technology to investigate the correlation of emotions among LD students during learning process. This shows that emotions for both parties (teachers and students) in the inclusive education setting are important to be examined in order to select an appropriate learning intervention and also assist in the learning process. It is noted that not only teachers' perspective is important to be investigated but should also include LD students' perspective so that a holistic view of inclusive education learning process can be analysed [15].

\section{EXPERIMENTAL DESIGN AND PROPOSED METHODOLOGY \\ Experimental Design}

Data will be collected and divided into two parts. Firstly in order to derive the ASM for each individual basic emotion stimuli is used while EEG signals recorded. Secondly the students' also need to complete another two tasks; 1) Clinching hands and 2) Matching game. The experimental design flow and protocol is shown in Figure 1 as a generalize experiments

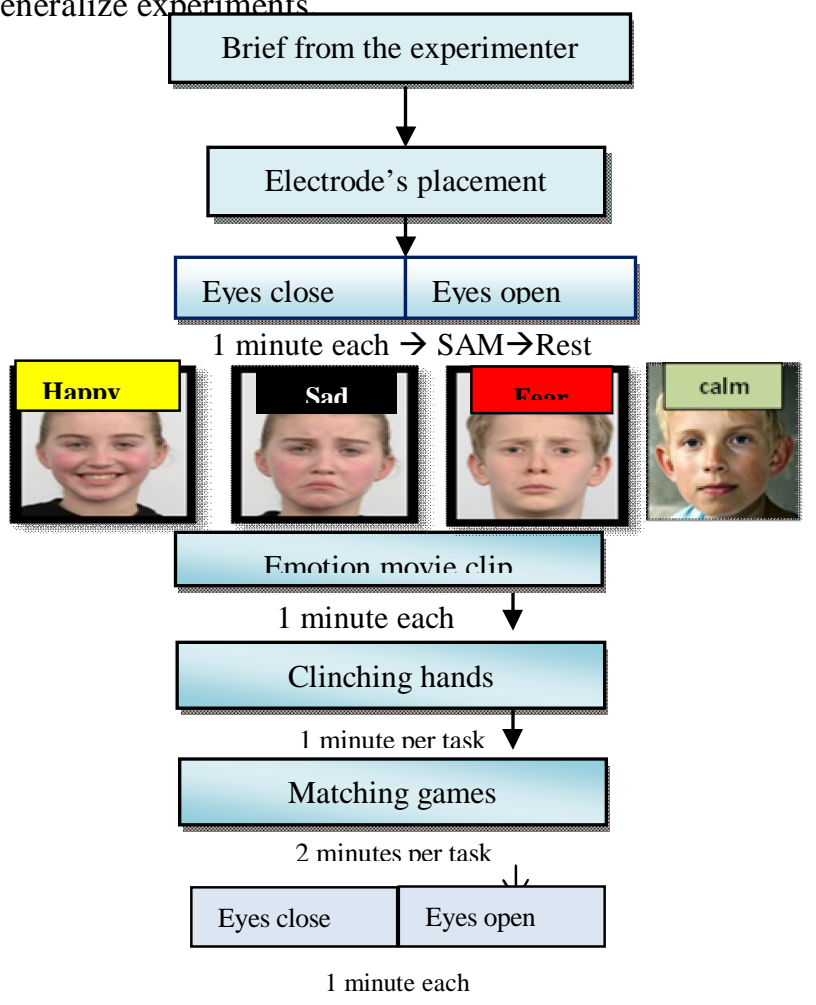

Figure 1: Experimental Design 


\section{Proposed Methodology}

Notice from Figure 2 both the eyes open and eyes close will provide initial information about the emotional state of the student. To ensure a proper initialization of the brain activity during eyes open task, student will be looking at a blank white screen. The four basic emotions movie clip will then be displayed for one and half minute per movie clip representing emotion happiness, fear, calmness, and sadness. After each movie clip, the student was required to fill up the Self-Assessment Manikin (SAM). Finally, student was requested to accomplish two types of tasks consisting of clinching hands and matching game. The final task is for the subjects to open and close their eyes for one minute each.

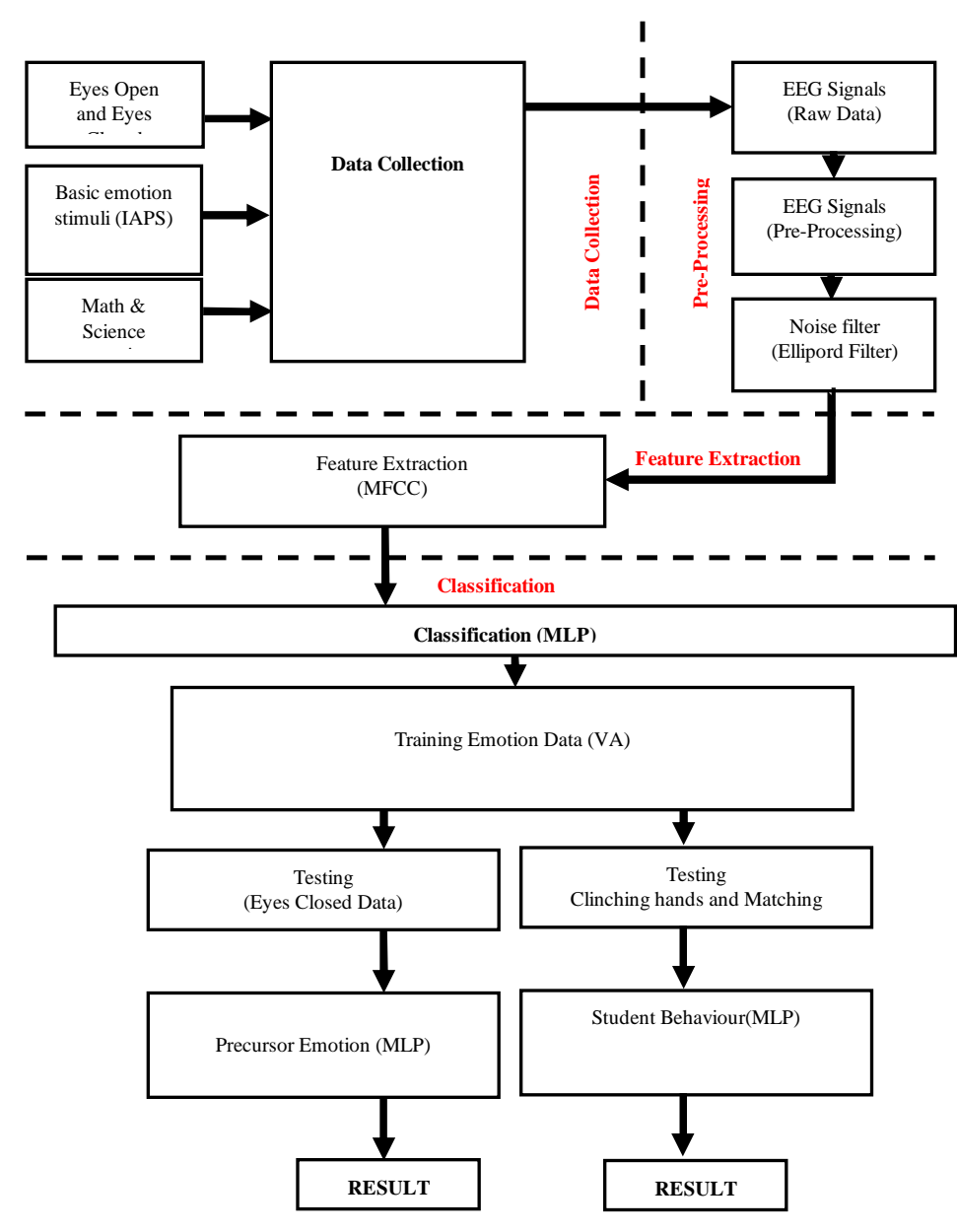

Figure 2: Proposed Methodology Diagram

\section{A. Stimuli}

The emotion's movie clips were used to obtain emotional responses and one set of mathematics test and science test to identify the student interest. Four basic emotions of happiness, fear, calmness and sadness from the International Affective Picture (IAPS) were used to generate the ASM references of each student. Bernard Bouchard's synthesized musical clips and Gross and Levenson's movie clips were used to elicit emotional responses [24] prior to the student doing the mathematics and science tests.

\section{B. Participants}

50 special needs and 50 mainstream students aged between 7 and 10 years old. This age group is selected to ensure sufficient and reliable measurement can be done for all learning disabilities children. In addition, participants will also be recruited through parents/primary caregiver through Penawar Special Learning Center (PSLC) with inclusion criteria; 1. Children age between 7 and 10 years old. 2. Autism, Attention-deficit/hyperactivity disorder (ADHD), Dyslexia, and Special Education Needs (SEN) children.

\section{Feature Extraction (MFCC)}

Based on our previous study [25], in this paper features were also extracted using MFCC to extract the low frequency EEG signals. Instead of using 40 MFCC coefficients like most feature extraction for speech, here only 10 MFCC coefficients were extracted and found to be sufficient. Thus, every instance will have 160 feature from 16 channels based on $256 \mathrm{nfft}$ points at $83 \mathrm{~Hz}$ sampling frequency and $20 \%$ overlap.

\section{MLP \\ Table 1: Training parameters for}

\begin{tabular}{|l|l|}
\hline No. of hidden layer & 1 \\
\hline No. of neuron in the hidden layer & 10 \\
\hline Activation function for hidden layer & tan-sig \\
\hline Activation function for output layer & $\begin{array}{l}\text { pureli } \\
\mathrm{n}\end{array}$ \\
\hline Learning rate & 0.01 \\
\hline Mean-square error goal & 0.1 \\
\hline
\end{tabular}

\section{Classification (MLP)}

MLP was adopted as the classifier in order to classify the extracted features to investigate the precursor emotion and its dynamic. A feed forward artificial neural network model, multi-layer perceptron maps sets of input data onto a set of appropriate output. Optimal model selection for the number of layer and the number of neuron needed for the best MLP architecture is required to ensure optimum performance. The training parameters for MLP is shown in Table 1.

\section{Evaluation and Analysis}

The final stage is evaluation and applying quantitative analysis to profile the student learning abilities and disabilities profiling in IE according to their emotion, behavior and mental state. It is commonly measured using several performance metrics of a computational model including the accuracy. In this stage, the emotion, behavior and mental state will be analyzed using valance arousal 
(VA) affective space model. VA will be used in this study by indicating a combination of threshold of 1 and -1 . Only then, we can identify the emotion (positive or negative emotion), behavior (pattern of emotion and mental state condition) and mental state either they are in stress or normal state.

\section{CONCLUSION}

Research in IE shows an absence of investigation on the relationship between emotion and learning ability among students in IE environment. This issue is important to be studied in order to understand the learning ability of students in the IE. Hence, this research paper is trying to propose a standard profiling model by using the Computational Neuro-physiological (CNP) model to profile lower primary school students in IE with assistance from EEG technology. A standard profiling model consists of students' emotions, behavior and mental state may help the development of interventions that can give a holistic view in the inclusive education's learning process. In addition, the profiling may enable the teachers to have better understanding on the learning ability of students in the inclusive education to enhance their teaching skills and competency.

\section{REFERENCES}

1. Anuar, A.A. and N.C. Rozubi, Keperluan pendidikan inklusif dalam program pendidikan arus perdana di Malaysia., in International Conference on Learner Diversity 2010. 2010: Fakulti Pendidikan, Universiti Kebangsaan Malaysia.

2. Cancio, E.J., et al., Special education teacher stress: Coping strategies. Education and Treatment of Children, 2018. 41(4): p. 457-481.

3. Engelbrecht, P., et al., Including learners with intellectual disabilities: Stressful for teachers? International Journal of Disability, Development and Education, 2003. 50(3): p. 293-308.

4. Forlin, C., J. Hattie, and G. Douglas, Inclusion: Is it stressful for teachers? Journal of Intellectual and Developmental Disability, 1996. 21(3): p. 199-217.

5. Kebbi, M., Stress and Coping Strategies Used by Special Education and General Classroom Teachers. International journal of special education, 2018. 33(1): p. 34-61.

6. Kiel, E., et al., How to cope with stress in special needs education? Stress-inducing dysfunctional cognitions of teacher students: the perspective of professionalisation. European Journal of Special Needs Education, 2016. 31(2): p. 202-219.

7. Fan, R.-E., P.-H. Chen, and C.-J. Lin, Working set selection using second order information for training support vector machines. Journal of machine learning research, 2005. 6(Dec): p. 1889-1918.

8. Jirayucharoensak, S., S. Pan-Ngum, and P. Israsena, EEG-based emotion recognition using deep learning network with principal component based covariate shift adaptation. The Scientific World Journal, 2014.
9. Jelas, Z.M. and M. Mohd Ali, Inclusive education in Malaysia: Policy and practice. International Journal of Inclusive Education, 2014. 18(10): p. 991-1003.

10. Khilnani, S., et al., Massage therapy improves mood and behavior of students with attention-deficit/hyperactivity disorder. ADOLESCENCE-SAN DIEGO-, 2003: p. 623638.

11. Alabdulakareem, E. and M. Jamjoom, Computer-Assisted Learning for Improving ADHD Individuals' Executive Functions Through Gamified Interventions: A Review. Entertainment Computing, 2020: p. 100341.

12. Mehmood, R.M. and H.J. Lee, Towards Building a Computer Aided Education System for Special Students Using Wearable Sensor Technologies. Sensors, 2017. 17(2): p. 317.

13. Bosse, I.K. and A. Pola. Applying movie and multimedia to the inclusive learning and teaching in Germany: Problems and solutions. in International Conference on Universal Access in Human-Computer Interaction. 2017. Springer.

14. Носенко, Ю. and Ж. Матюх. The implementation of multimedia technology in ukrainian inclusive preschool education. in Proceedings of the 13th International Conference on ICT in Education, Research and Industrial Applications. Integration, Harmonization and Knowledge Transfer Kyiv, Ukraine, May 15-18, 2017. 2017. CEUR Workshop Proceedings.

15. Daniela, L. and M.D. Lytras, Educational robotics for inclusive education. 2019, Springer.

16. Hossain, M.S., Patient state recognition system for healthcare using speech and facial expressions. Journal of medical systems, 2016. 40(12): p. 272.

17. Jenke, R., A. Peer, and M. Buss, Feature extraction and selection for emotion recognition from EEG. IEEE Transactions on Affective Computing, 2014. 5(3): p. 327339.

18. Imani, M. and G.A. Montazer, A survey of emotion recognition methods with emphasis on E-Learning environments. Journal of Network and Computer Applications, 2019: p. 102423.

19. Li, T.-M., et al. Analysis of Students' Learning Emotions Using EEG. in International Conference on Innovative Technologies and Learning. 2019. Springer.

20. Tambe, N.R. and A. Khachane. Mood based E-learning using EEG. in 2016 International Conference on Computing Communication Control and automation (ICCUBEA). 2016. IEEE.

21. Xu, T., et al., Learning emotions EEG-based recognition and brain activity: A survey study on BCI for intelligent tutoring system. Procedia computer science, 2018. 130: p. 376-382.

22. Pop-Jordanova, N., ADHD as a Specific Cause for Learning Disability, in Learning Disabilities. 2020, IntechOpen.

23. Gopalakrishnan, A., Assessing the use of immersive environments for preparing teachers to address challenging student behaviors. Master Thesis, University of Canterbury, New Zealand, 2020.

24. Chanel, G., Kronegg, J., Granjean, D., \& Pun, T. (2006). Emotion assessment: Arousal evaluation using EEG's 
Norzaliza Md Nor et al., International Journal of Advanced Trends in Computer Science and Engineering, 10(3), May - June 2021, 1515 - 1519

and peripheral physiological signals. Proceedings International Workshop on Multimedia Content Representation, Classification and Security, Istanbul, pp. 530-537.

25. Wahab, A., Kamaruddin, N., M. Nor, N., Abut, H., "Preand Postaccident Emotion Analysis on Driving

Behavior", Smart Mobile In-Vehicle Systems, 225-239, 2014 